\title{
ECTOPIA CORDIS: DIAGNÓSTICO ECOGRÁFICO EN EL SEGUNDO TRIMESTRE DE LA GESTACIÓN
}

\author{
Héctor G Quiroga. 1 \\ 1 Centro Médico ROSANCAR, Barquisimeto, Estado Lara, Venezuela.
}

\section{RESUMEN}

Se presenta un caso clínico de ectopia cordis. Se discute el desarrollo embriológico, la metodología diagnóstica y el pronóstico perinatal.

\section{PALABRAS CLAVES: Ectopia cordis, diagnóstico prenatal}

\section{SUMMARY}

A clinical case of ectopia cordis is reported. The embryologic development, the prenatal diagnosis method and the perinatal outcome is discussed.

\section{KEY WORDS: Ectopia cordis, prenatal diagnosis}

\section{INTRODUCCIÓN}

El término de ectopia cordis, ectocardia o exocardia se refiere al desplazamiento total o parcial del corazón fuera de la cavidad toráxica (1), tiene una incidencia aproximada de 5,5 a 7,9/ millón de nacidos vivos (2). A continuación se presenta un caso clínico de esta patología, su clasificación, antecedentes embriológicos y pronóstico perinatal.

\section{CASO CLINICO}

Paciente primigesta de 19 años de edad, sin antecedentes personales de importancia quien inició su control prenatal a las 8 semanas de gestación, en esa oportunidad se le practicó ultrasonido intravaginal que reporto gestación única intrauterina y embrión con actividad cardiaca presente. Consulta nuevamente a las 22 semanas para su control prenatal rutinario practicándosele durante el mismo ultrasonido que reporta: feto único, situación longitudinal, biometría fetal de 20 semanas. El estudio detallado de la anatomía fetal demuestra solución de continuidad en labio superior. Tórax con defecto del cierre de la pared anterior del mismo, a través del cual se exterioriza el corazón a la cavidad amniótica (Figuras 1 y 2), frecuencia cardiaca fetal de 136 latidos/min, se identificaron las cuatro cámaras cardiacas, no se apreciaron defectos a nivel de tabique interauricular e interventricular; válvulas AV, pulmonar y aórtica indemnes. A nivel de abdomen se identificó defecto de cierre de la pared anterior a través del cual se exteriorizaba el hígado en su totalidad (Figura 3). Cordón umbilical con sus tres vasos sin defectos a nivel de su inserción abdominal. Resto del estudio sin alteraciones. Se practicó doppler color y tridimensional confirmándose los hallazgos antes descritos (Figura 4).

Dos semanas posteriores a la evaluación ecográfica la paciente desencadena trabajo de parto espontáneo. La anatomía patológica revela (Figura 5): feto masculino con defecto en línea 

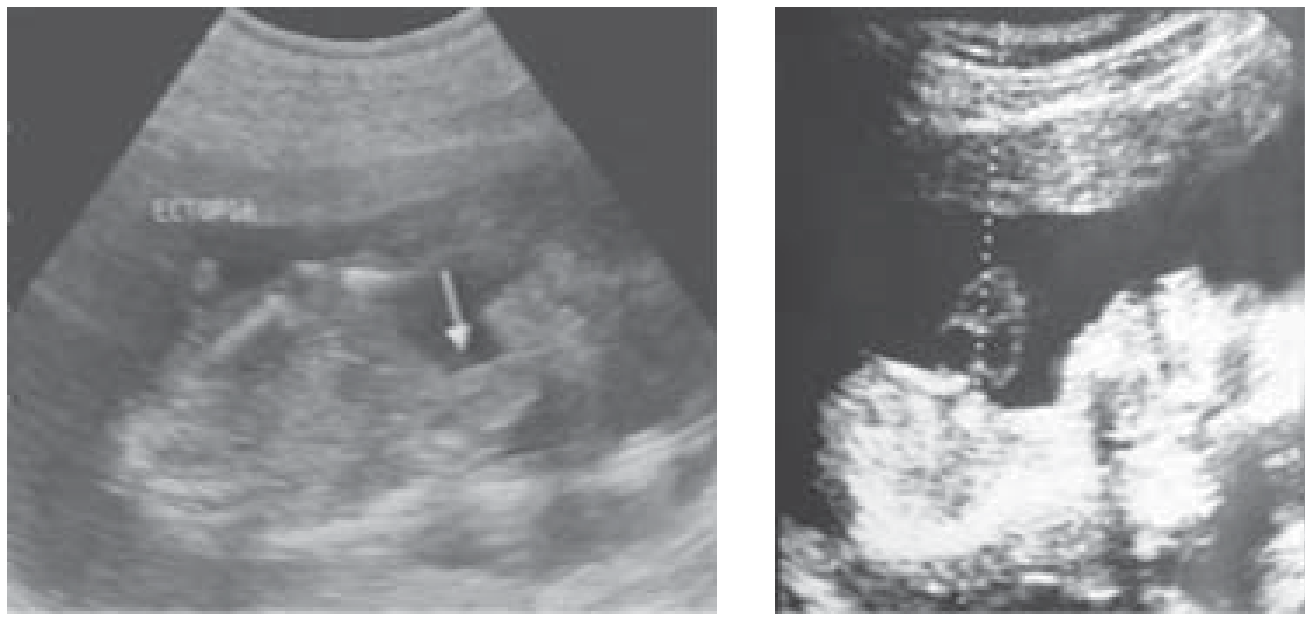

Figura 1 y 2. Imágenes que demuestran la Ectopia Cordis

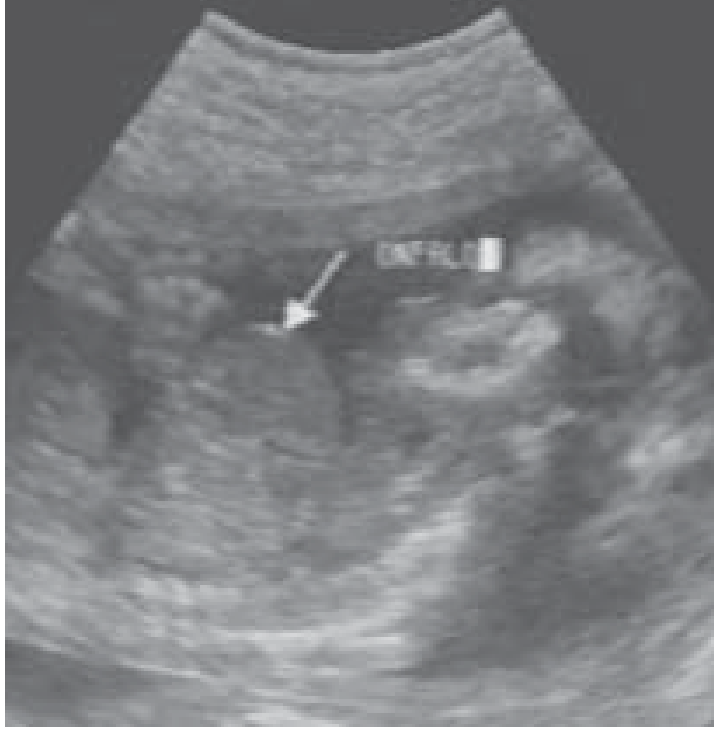

Figura 3. Defecto de la pared abdominal.

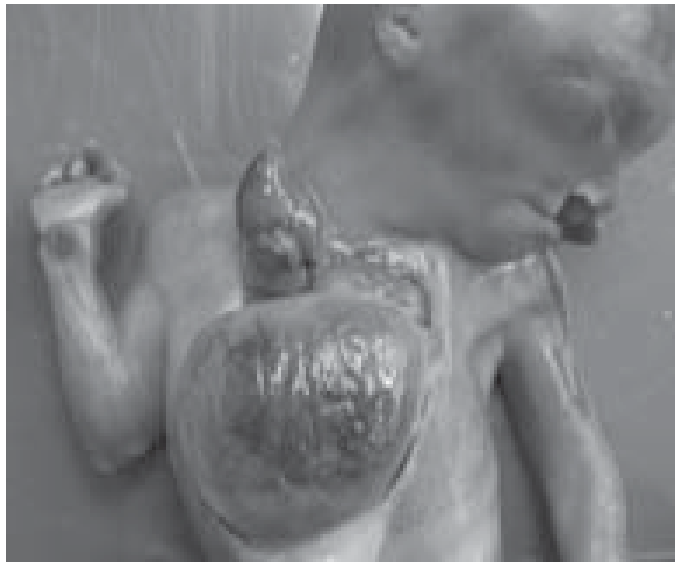

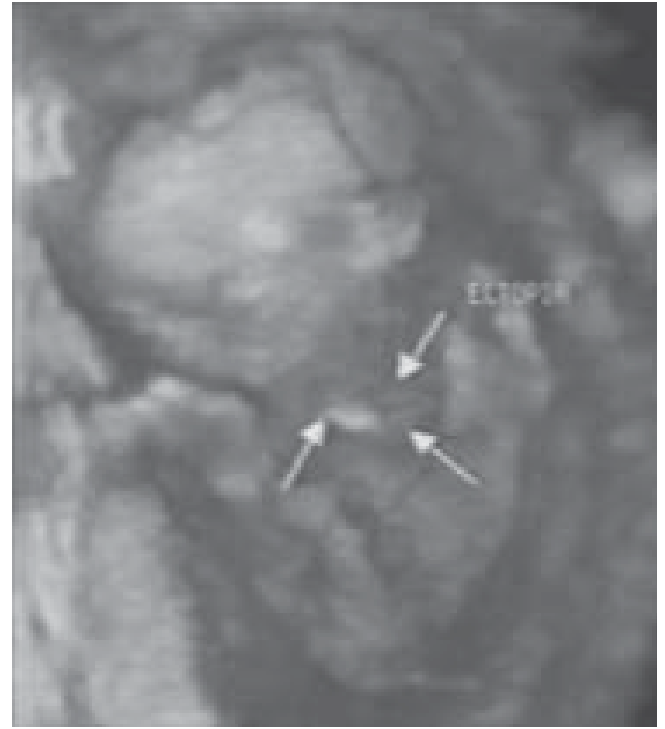

Figura 4. Reconstrucción en 3D.

media de la cara tipo fisura labio-palatina, a nivel del tórax ausencia total de esternón y parte anterior de arcos costales, corazón con cuatro cavidades, ubicado fuera de la cavidad toráxica, ausencia de pericardio, ausencia de defectos septum interauricular e interventricular, concordancia veno-atrial, atrio-ventricular y ventrículo-arterial, diafragma anterior ausente. Pulmones derecho e izquierdo sin alteraciones, además defecto en pared abdominal anterior a través del cual se exterioriza el hígado, bazo infradiafragmático izquierdo, vías urinarias y suprarrenales sin alteraciones, testículos no descendidos de localización intrapélvica.

Figura 2. Hallazgos anatomopatológicos 
Cordón umbilical con sus tres vasos sin defectos a nivel de su inserción abdominal.

\section{DISCUSIÓN}

Según la ubicación del corazón la ectopia cordis se ha clasificado en 5 tipos $(1,3,4)$ :

- Cervical, el corazón se encuentra en el cuello y el esternón esta intacto.

- Toracocervical, el corazón se exterioriza a través de un defecto en la porción superior del esternón $(1,4)$.

- Toráxico, existe un defecto esternal y el corazón protruye a través de la pared anterior del tórax $(4,5)$.

- Toracoabdominal, el defecto se encuentra en la porción inferior del esternón y epigastrio (1, 4, $5)$.

- Abdominal, el esternón esta indemne y una solución de continuidad en el diafragma permite el desplazamiento del corazón al abdomen superior $(1,4,5)$.

Las causas de esta malformación son desconocidas (6). Sin embargo, se cree que la forma cervical podría deberse a un fallo en el desplazamiento del corazón desde su ubicación primitiva en el cuello a la cavidad toráxica $(1,4)$. Otras formas de ectopia cordis pudieran representar un desarrollo anormal del mesodermo entre los días 14 a 18 de vida intrauterina $(3,7,8,9)$. Por otra parte los defectos de la pared toráxica y abdominal son un resultado de una falla en la fusión ventromedial de los pliegues corporales $(3,7)$. En la variedad toracoabdominal el defecto ocurre a nivel del septum transverso el cual es la estructura que forma la porción anterior del diafragma y parte del pericardio $(3,7)$.

La ectopia cordis puede ser parte del síndrome de banda amniótica $(5,11,12)$ del Limb Body Wall Complex $(1,2)$ o de la Pentalogía de Cantrell, (3, $7,10)$ este último caracterizado por la presencia de ectopia cordis, deficiencia del pericardio anterior, solución de continuidad en el esternón y en la porción anterior del diafragma y malformaciones cardiacas.

La ectopia cordis puede ser diagnosticada prenatalmente por ultrasonido mediante la visualización del corazón fetal latiendo fuera de la cavidad toráxica $(3,5-8,12)$ por otra parte debido a que este defecto se encuentra presente desde la embriogénesis, su diagnóstico puede ser realizado en etapa tempranas del embarazo $(1,5,6,11)$. En la mayoría de los casos asociado a la ectopia cordis, pueden encontrarse defectos estructurales intracardíacos $(1,3)$ y extracardíacos como onfaloceles (1), gastrosquisis, defectos del tubo neural, fisuras labiopalatinas, y una gran variedad de malformaciones esqueléticas $(1,3,7)$.

Las cromosomopatías son infrecuentes por lo que no se aconseja practicar cariotipo $(1,7)$, sin embargo, existen casos en la literatura donde este trastorno se ha asociado a trisomía 18, 13 y síndrome de Turner $(3,6)$. Esta patología tiene un mal pronóstico $(3,6,7)$ y por lo tanto la sobrevida es infrecuente por lo que la interrupción del embarazo debe ser considerada si el diagnóstico es realizado antes de la viabilidad. Si el paciente decide continuar con el embarazo, no existen datos que indiquen que la cesárea mejore la evolución del cuadro.

\section{BIBLIOGRAFÍA}

1. Hagler DJ, O'Leary PW: Cardiac malpotitions and abnormalities of atrial and visceral situs. In: Emmanouilides GC, Riemenschneider TA, Allen HD, et el (eds): Heart Diseases in Infants, Children, and Adolescents Including the Fetus and Young Adult, 5th ed. Baltimore, William and Wilkins, 1995, pp 1307-1336.

2. Homberger LK, Colan SD, Lock JE, Wessel DL, Mayer JE. Outcome of patients with ectopia cordis and significant intracardiac intracardiac defects. Circulation 1996; 49: 32-37.

3. Ghidini A, Sistori M, Romero R. Prenatal diagnosis of pentalogy of Cantrell. J Ultrasound Med 1988; 7 : 567-572.

4. Dobell ARC, Williams HB, Long RW: Staged repair of ectopia cordis. J Pediatr Surg 1982; 17: 353-358.

5. Fleming AD, Vintzilieos AM, Rodis JF. Diagnosis of fetal ectopia cordis by transvaginal ultrasound. J Ultrasound Med 1991; 10: 413-415.

6. Klingensmith WC III, Cioffi-Ragan DT, Harvey DE. Diagnosis of ectopia cordis in the second trimester. J Clin Ultrasound 1988; 16: 204-206.

7. Abu-Yousef MM, Wray AB, Williamson RA. Antenatal ultrasound diagnosis of variant of pentalogy of Cantrell. J Ultrasound Med 1987; 6: 535-538.

8. Wicks JD, Levine MD, Mettler FA Jr. Intrauterine sonography of thoraxic ectopia cordis. AJR 1981; 137: 619-621.

9. Haynor DR, Shuman WP, Brewer DK. Imaging of fetal ectopia cordis: Roles of sonography and computed tomography. J ultrasound Med 1984; 3 : 25-27.

10. Deneath FM, Romano W, Solcs M. Ultrasonographic findings of exencephaly in pentalogy of Cantrell: Case report an review of the literature. J Clin Ultrasound 1994; 22: 351-354. 
11. Bieber FR, Mostoufi-Zadeh M, Birnholz JC, et al. Amniotic band sequence associated with ectopia cordis in one twin. J Pediatr 1984; 105: 817-819.
12. Patten RM, Van Allen M, Mack LA, et al. Limb-body wall complex: In utero sonographic diagnosis of a complicated fetal malformation. AJR 1986; 146: 1019-1024. 